\title{
Investigating Detect-and-Avoid Surveillance Performance for Unmanned Aircraft Systems
}

Chunki Park and Seung Man Lee University Affiliated Research Center / UC Santa Cruz

\section{Eric Mueller} NASA Ames Research Center

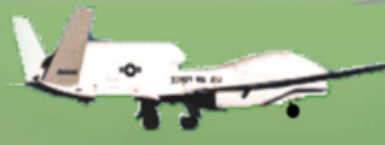
SC-228 Meeting, Washington D.C. Aug $25-28,2014$

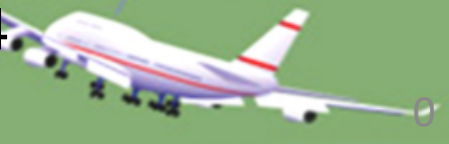




\section{Background and Motivation}

- A Detect-And-Avoid (DAA) capability is required for UAS to meet the requirement in CFR 91.113 to "see and avoid" other aircraft and maintain "well clear".

- RTCA Special Committee 228 is developing Minimum Operational Performance Standards (MOPS) for DAA systems.

- A surveillance system is a critical component of DAA system to detect and track intruder aircraft. Thus, the MOPS will include surveillance system requirements.

- Encounter characteristics of "well-clear" violations between UAS and manned aircraft have not been investigated. 


\section{Objectives}

- Investigate geometric encounter characteristics of well-clear violations between UAS and VFR aircraft in Class E airspace

- Investigate the relationship between encounters and surveillance system characteristics in terms of detection range and field of regard (FOR)

- Generate a database for encounters between UAS and VFR aircraft and a knowledge base that helps surveillance system designer 


\section{Concept of Well-Clear Violation}

- Airborne separation standard

- Time and distance-based definition of "Well-Clear Violation (WCV)"

- When two aircraft are within distance thresholds

- When the projected closest point of approach (CPA) of two aircraft is within a distance-based volume in particular time thresholds

\section{"Well Clear" Distance Thresholds}

Horizontal criteria

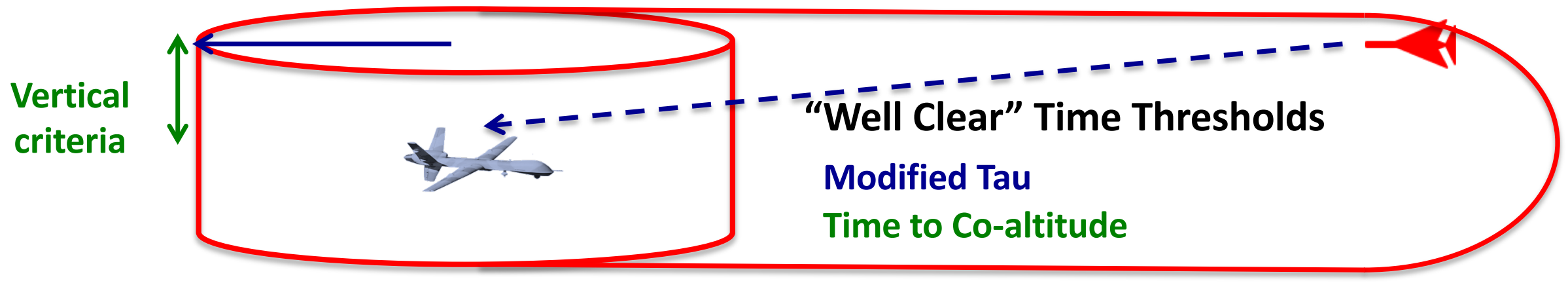




\section{Definition of Well-Clear Violation}

Horizontal Criteria $R_{x y} \leq D M O D$ or $\left\{R_{x y}\left(t_{C P A}\right) \leq H M D\right.$ and $\left.0 \leq \tau_{\text {mod }} \leq \tau_{\text {mod }}^{*}\right\}$

and

Vertical Criteria

$$
|\Delta h| \leq Z T H R \quad \text { or } \quad 0 \leq \tau_{\text {vert }} \leq \tau_{\text {vert }}^{*}
$$

where $R_{x y}$ : Horizontal Range

$R_{x y}\left(t_{C P A}\right)$ : Predicted horizontal range at time of closest point of approach

$\tau_{\text {mod }}$ : Modified Tau $\left\{\begin{array}{cl}-\frac{R_{x y}^{2}-D M O D^{2}}{R_{x y} \dot{R}_{x y}} & \text { for } R_{x y}>D M O D \\ 0 & \text { for } R_{x y} \leq D M O D\end{array}\right.$

$|\Delta h|:$ Altitude Difference

$\tau_{\text {vert }}:$ Time to Co-Altitude

$D M O D=6000 \mathrm{ft} \quad H M D=6000 \mathrm{ft} \quad$ ZTHR $=475 \mathrm{ft}$

$\tau_{\text {mod }}^{*}=30 \mathrm{sec} \quad \tau_{\text {vert }}^{*}=20 \mathrm{sec}$ 


\section{Generic Surveillance Model}

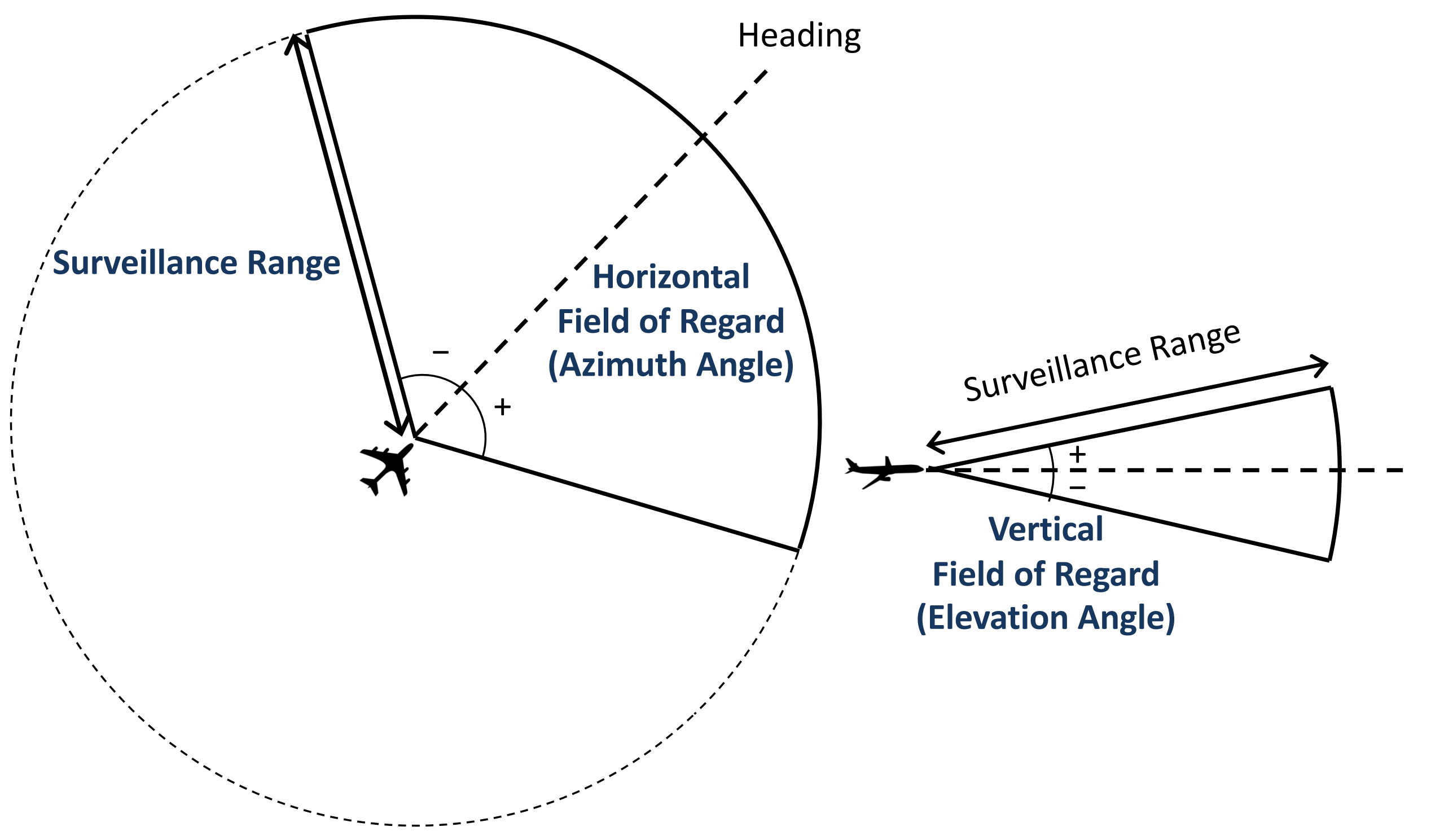




\section{Generic Surveillance Model}

Surveillance Volume

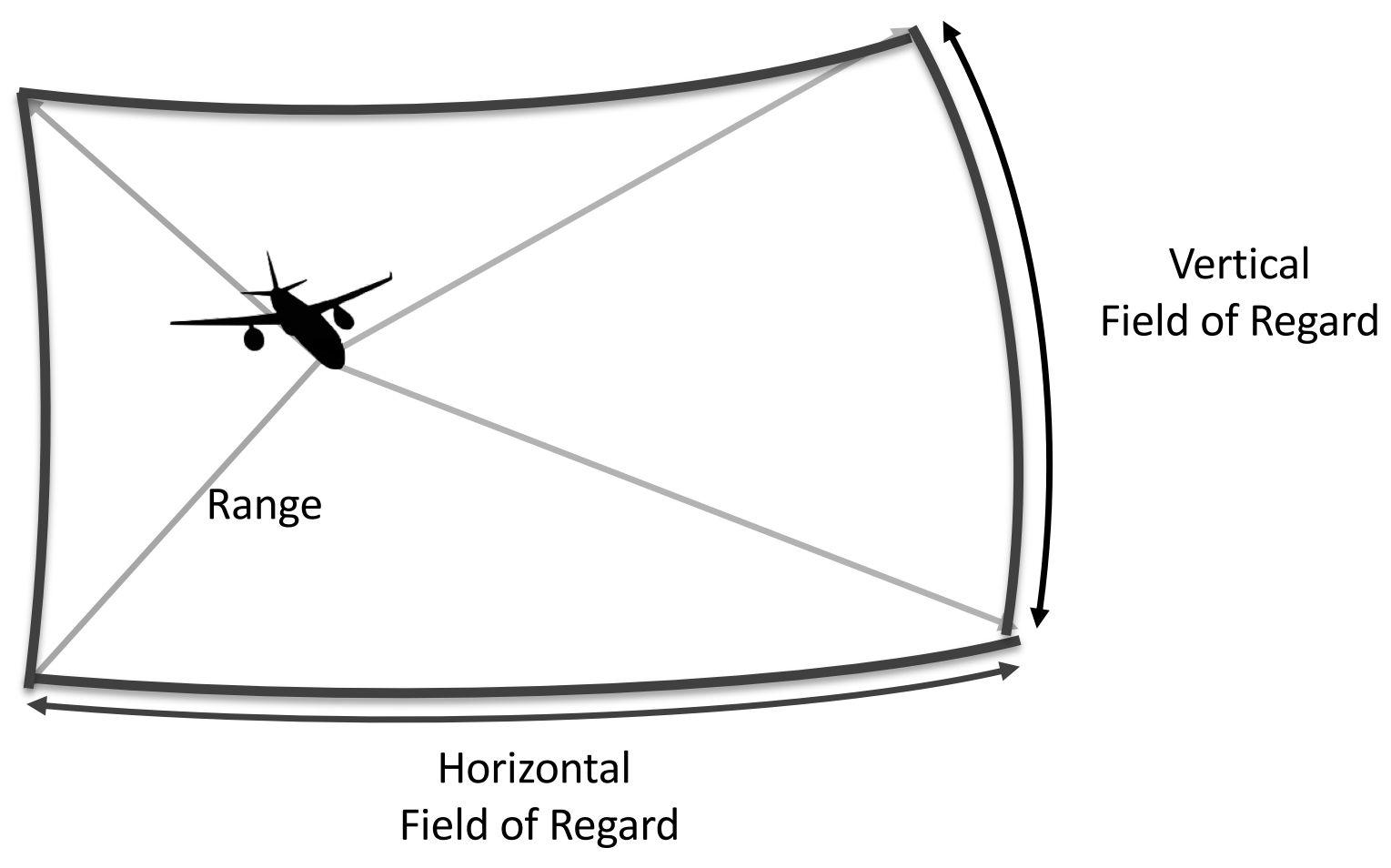




\section{Intruding event, Intruder and Threat}

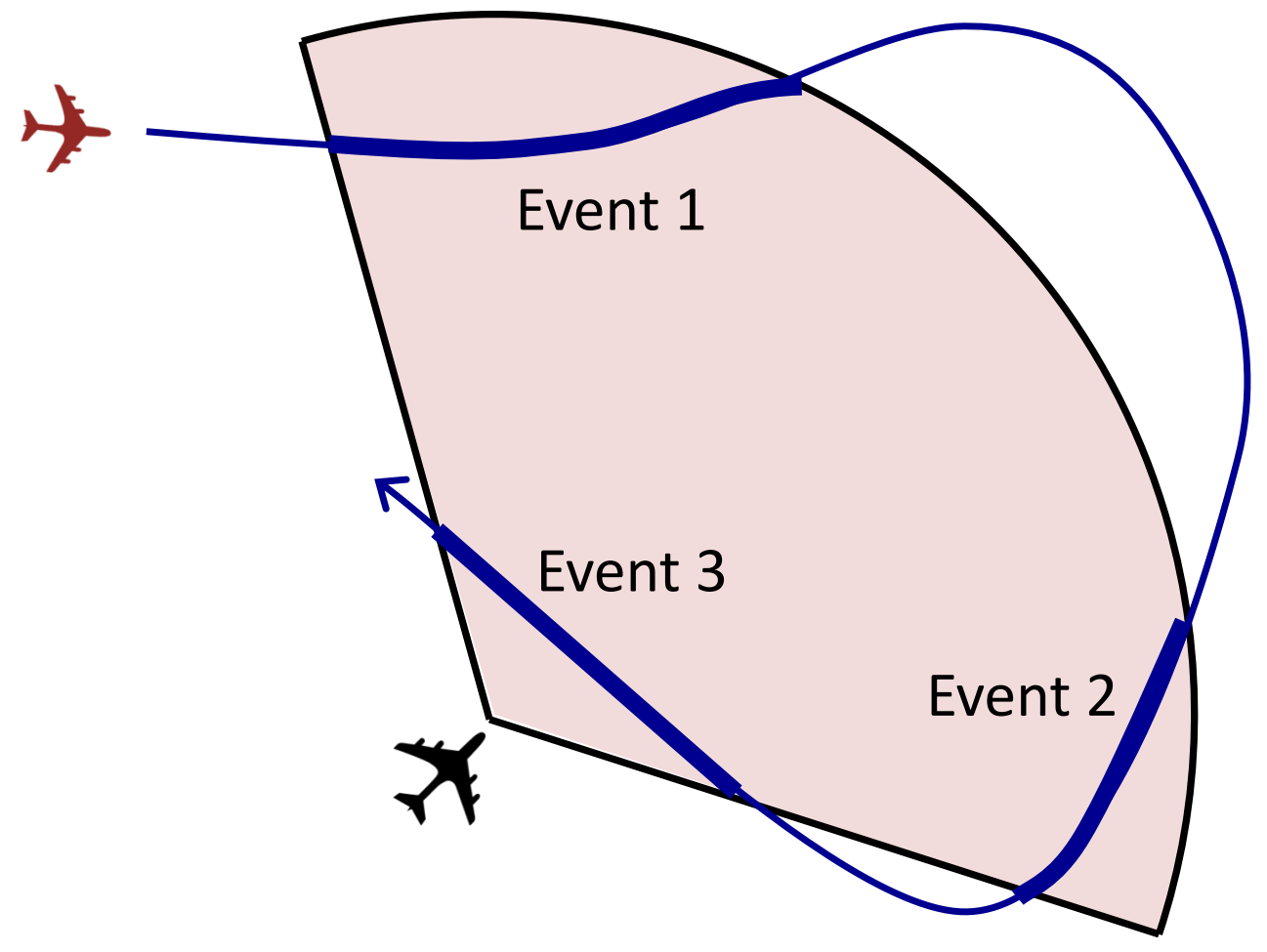

- Intruding event: Each intrusion into the ownship's surveillance volume

- Intruder: Aircraft that causes intruding events

- Threat: An intruder that finally causes well-clear violation 


\section{NAS-Wide Air Traffic Simulation}

- Airspace Concept Evaluation System (ACES)

- Simulate NAS-wide air traffic operations and unmitigated encounters between UAS and VFR traffic

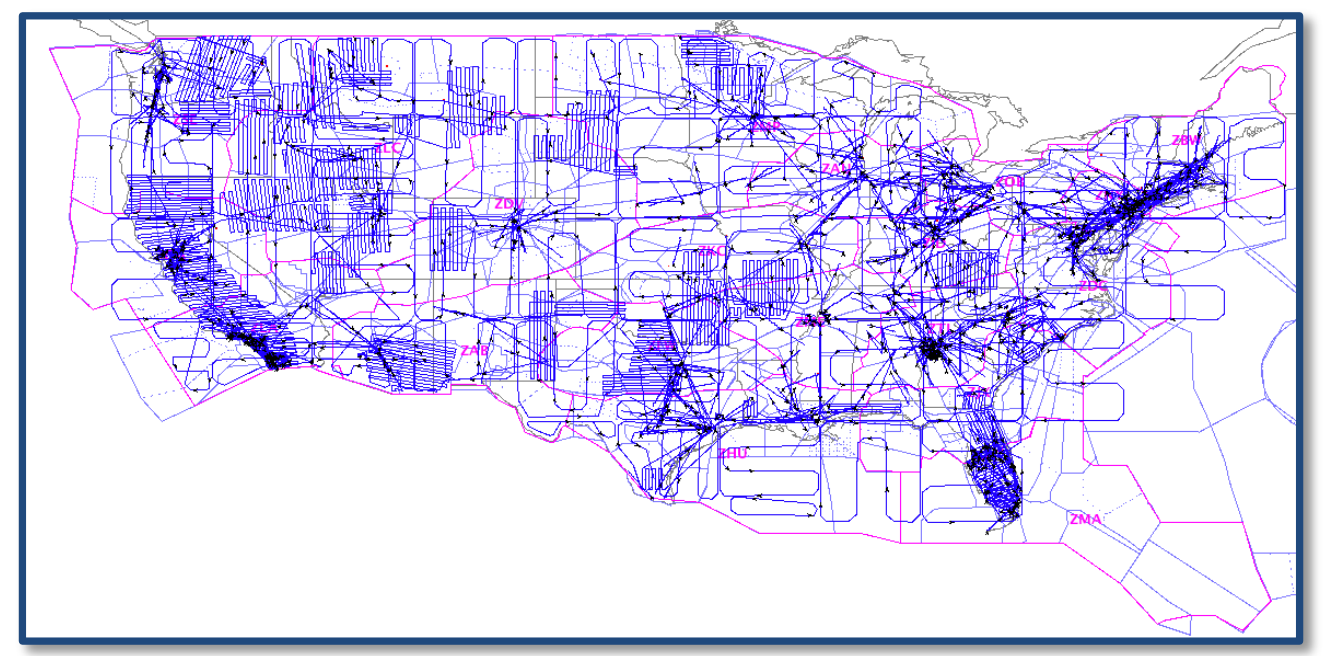

- Traffic scenarios

-Proposed UAS flights

- Various types of UAS missions generated by Intelligent Automation Inc.

- Total 18,262 flights, 18,900 flight hours

-Historical cooperative VFR traffic

- Extracted from Air Defense radar data on 2012

- Selected 7 days: $1 / 5,4 / 6,4 / 21,7 / 2,7 / 22,7 / 25$, and 10/16

- Each day: 20,439-26,770 flights, 16,515-24,838 flight hours 


\section{Simulation and Analysis}




\section{Relative Position of Threats}

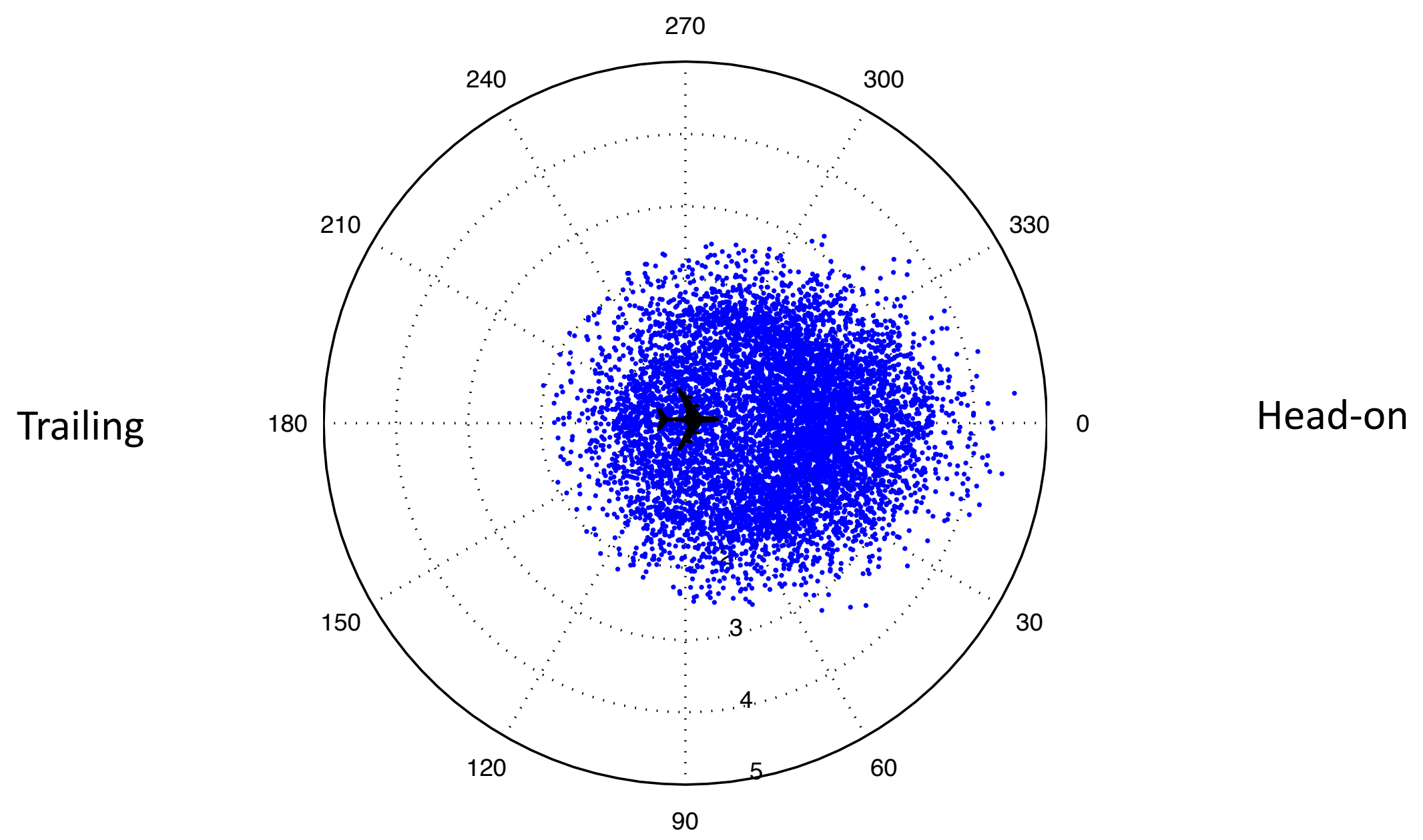

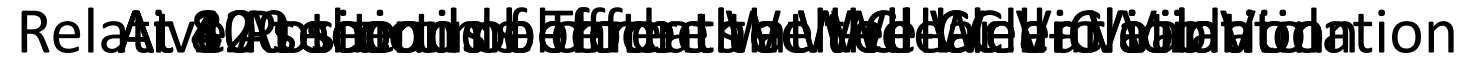




\section{Bearing Angle Distribution at Well-Clear Violation}

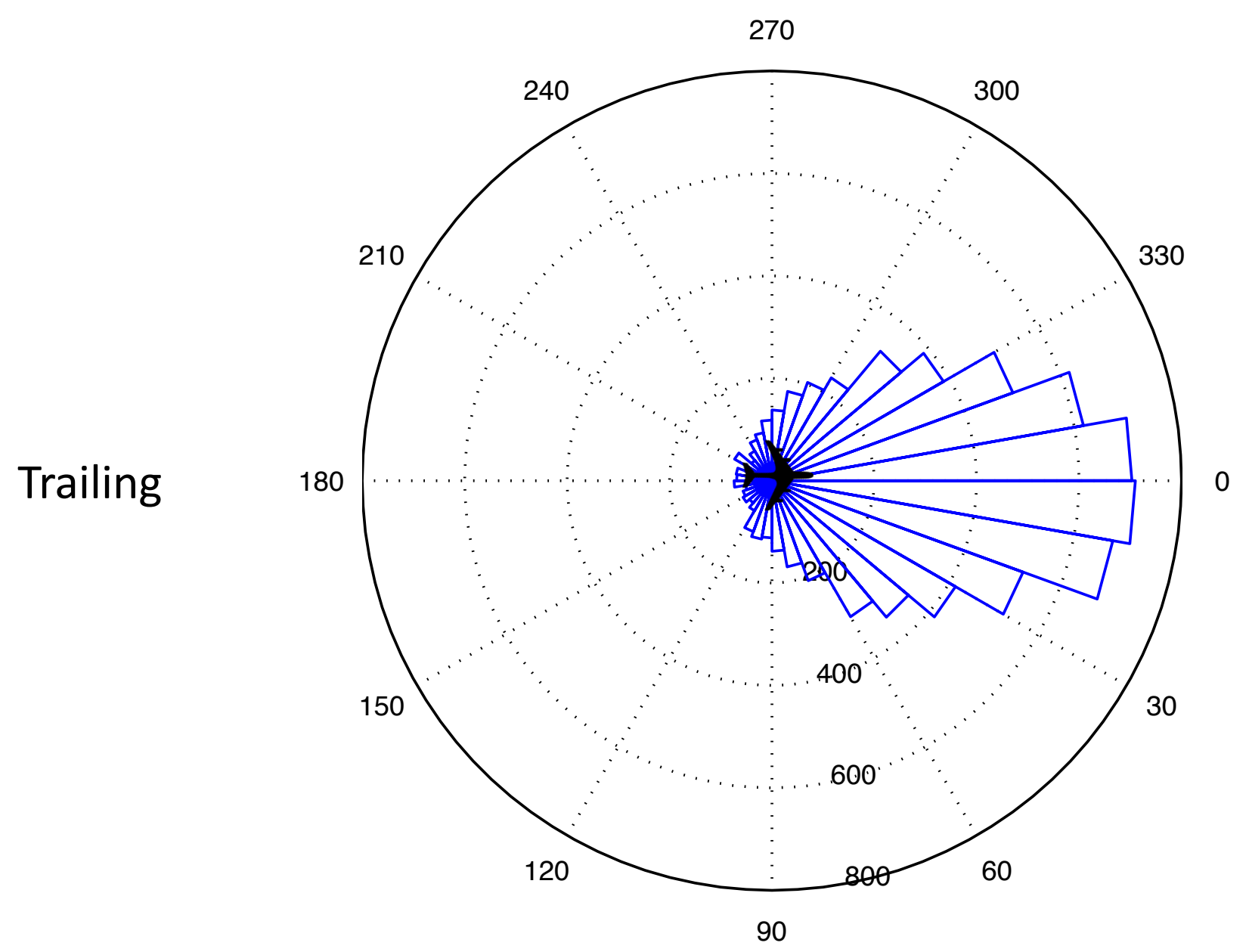

Head-on 


\section{Relative Horizontal Distance of Threats}

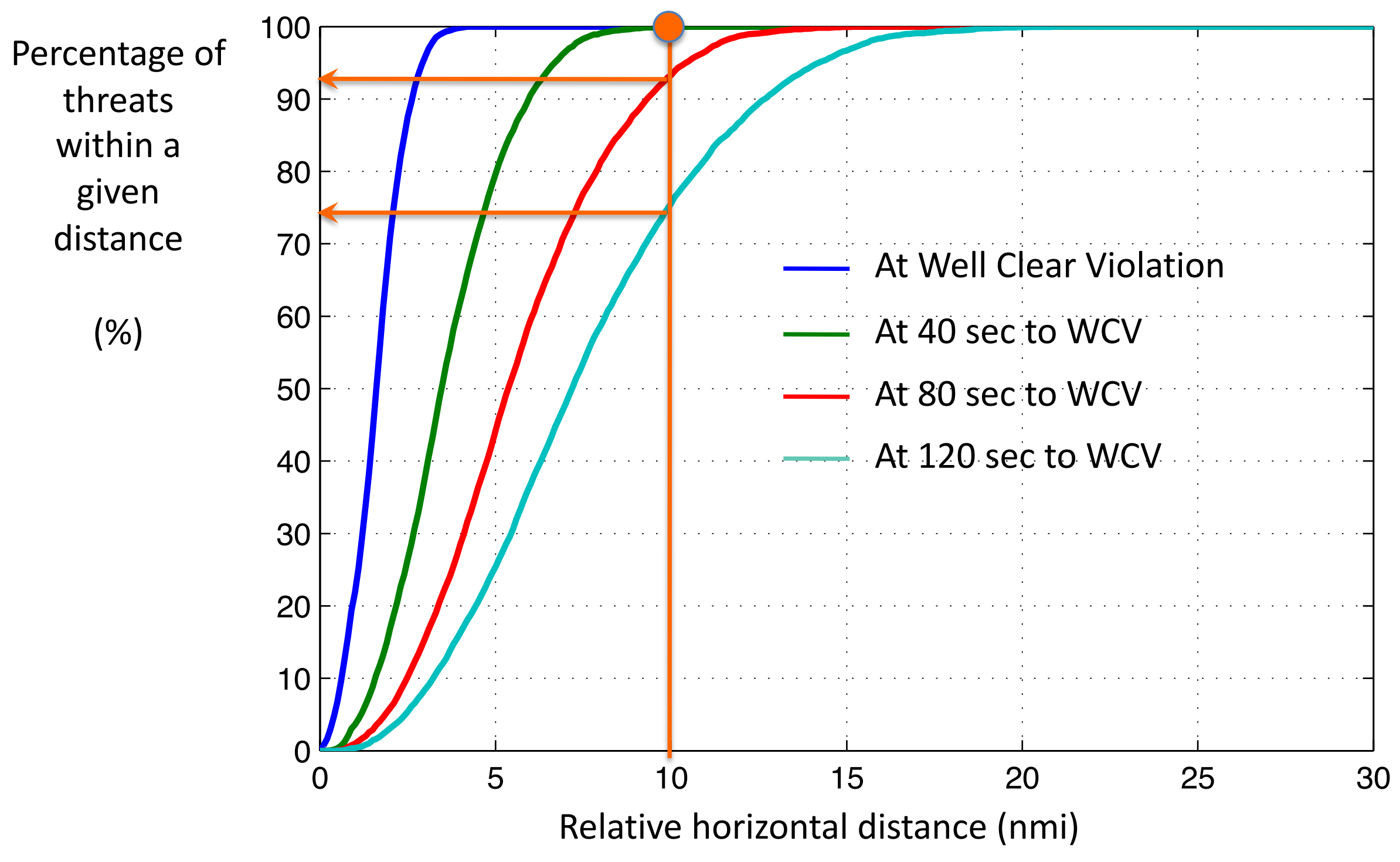


NAsA Relative Horizontal Angle of Threats

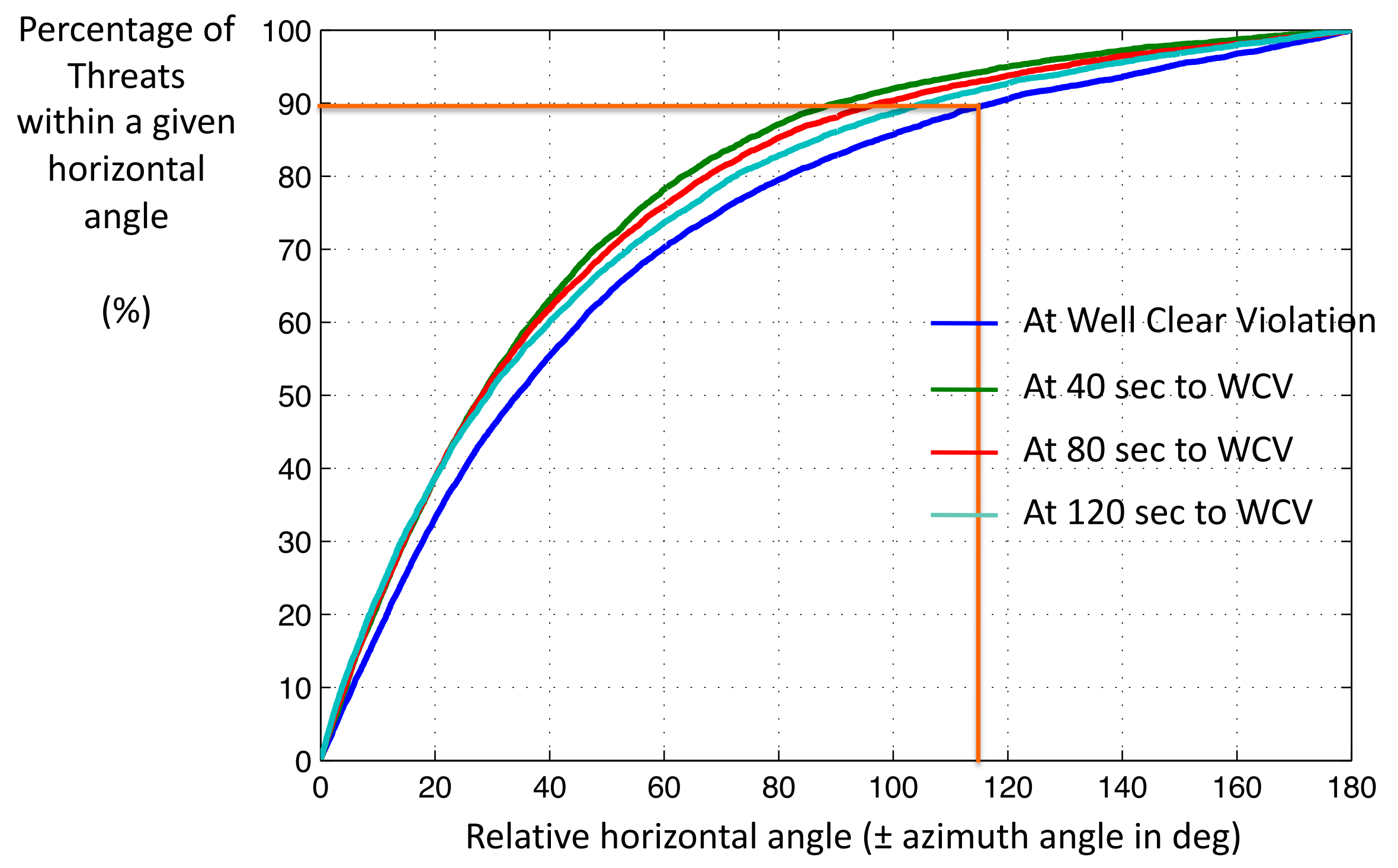




\section{Relative Vertical Angle of Threats}

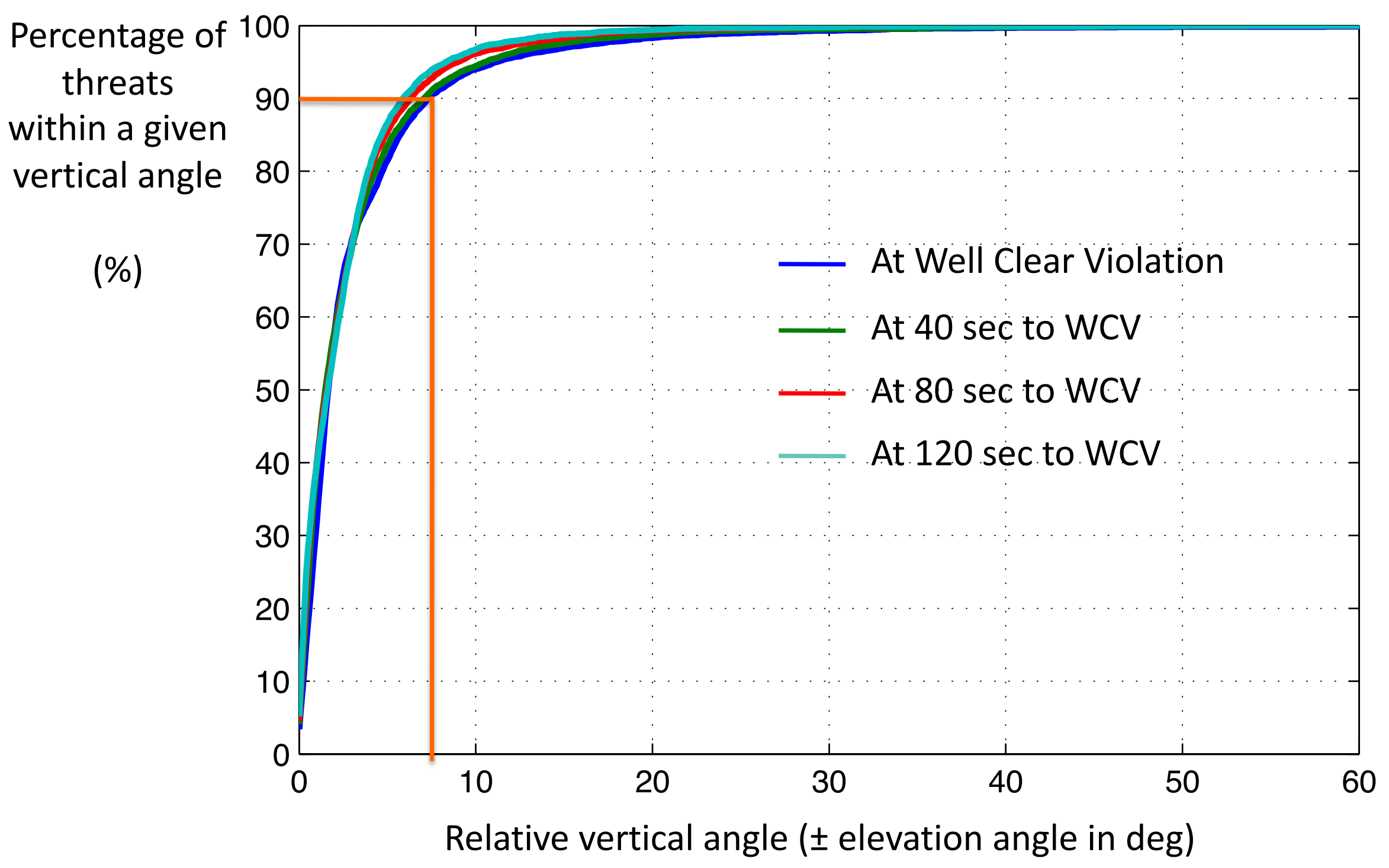




\section{Effects of Surveillance Parameters}

- Selected sets of surveillance parameters

- Surveillance Range: 3, 6, 10, $20 \mathrm{nmi}$

- Horizontal Field of Regard: ( \pm ) 60, 90, 120, $180 \mathrm{deg}$

- Vertical Field of Regard: ( \pm ) 20, 40 deg

- Total 32 sets of surveillance volume $\left(4^{\star} 4^{\star} 2\right)$

- Analysis for undetected Well-Clear Violation

- Metric: Ratio of the number of undetected Well-Clear Violations for each surveillance volume

- Analysis for detected Well-Clear Violation

- Metric: Time to Well-Clear Violations of threats at their first appearance in each surveillance volume 


\section{Detected / Undetected / Late-Detected Well-Clear Violations}

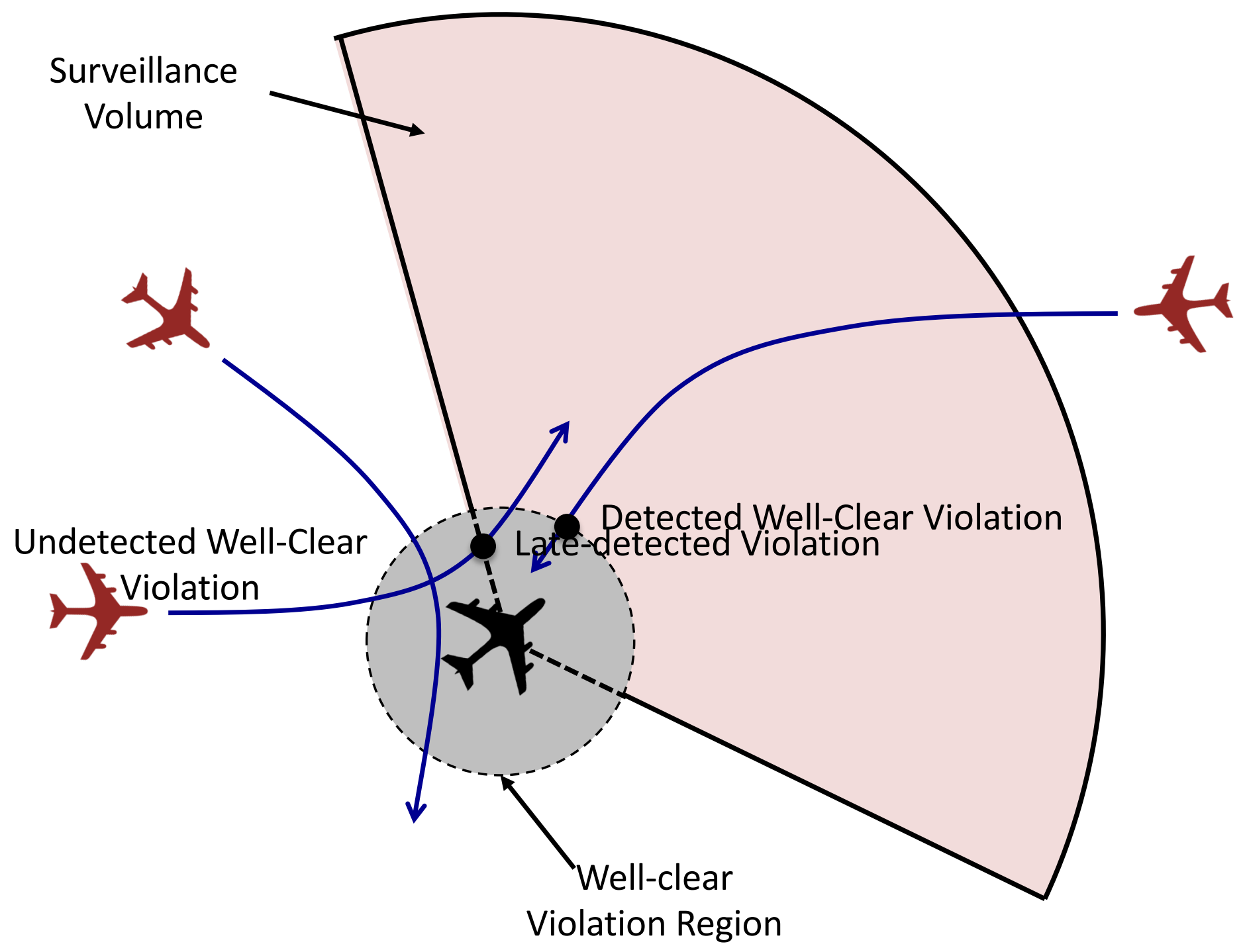




\section{Ratio of Undetected and Late-detected Well-Clear Violations}

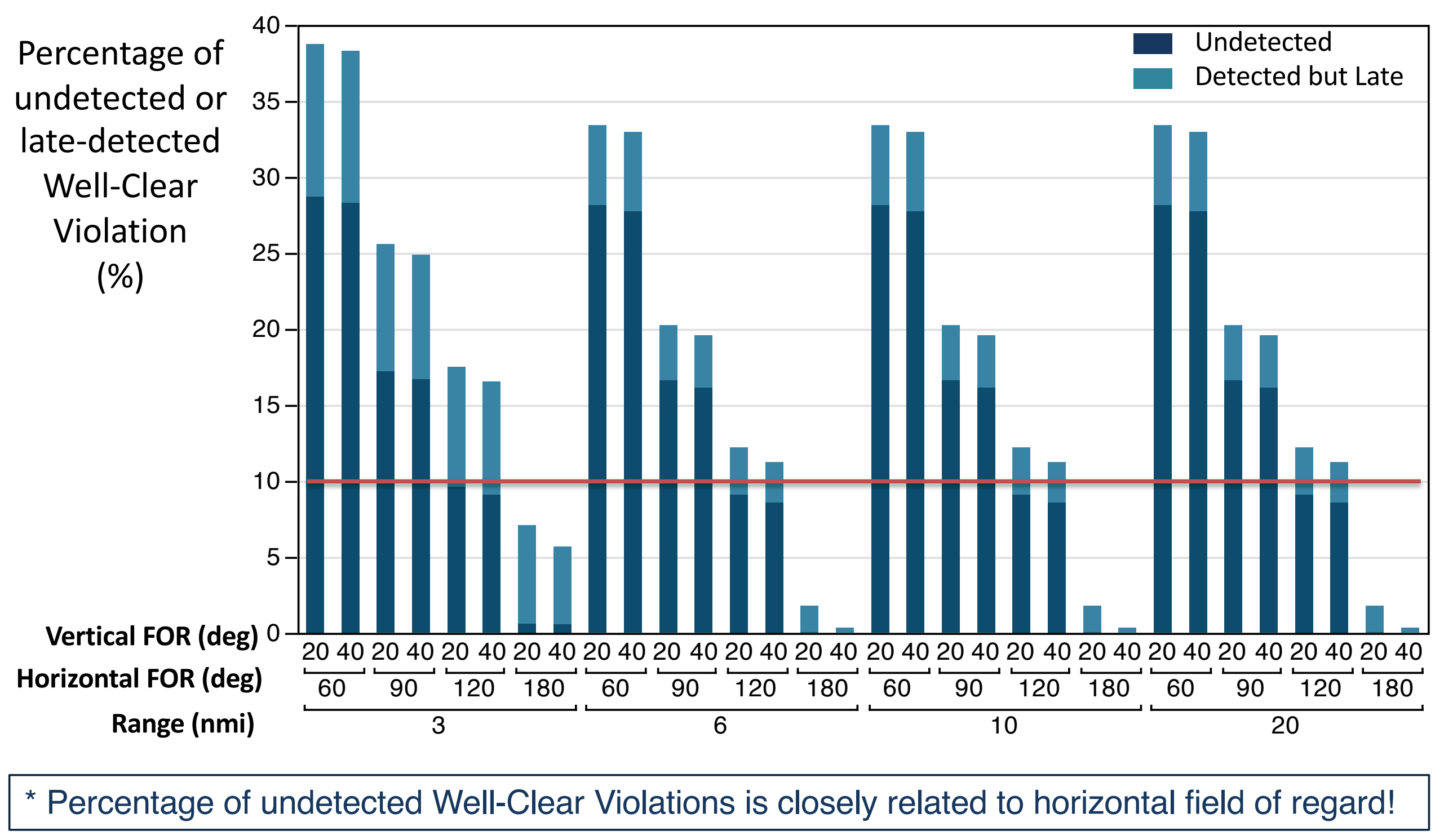


- When range=10 $\mathrm{nmi}, \mathrm{HFOR}=120 \mathrm{deg}, \mathrm{VFOR}=20 \mathrm{deg}$

Cumulative distribution for horizontal distance

$\%$

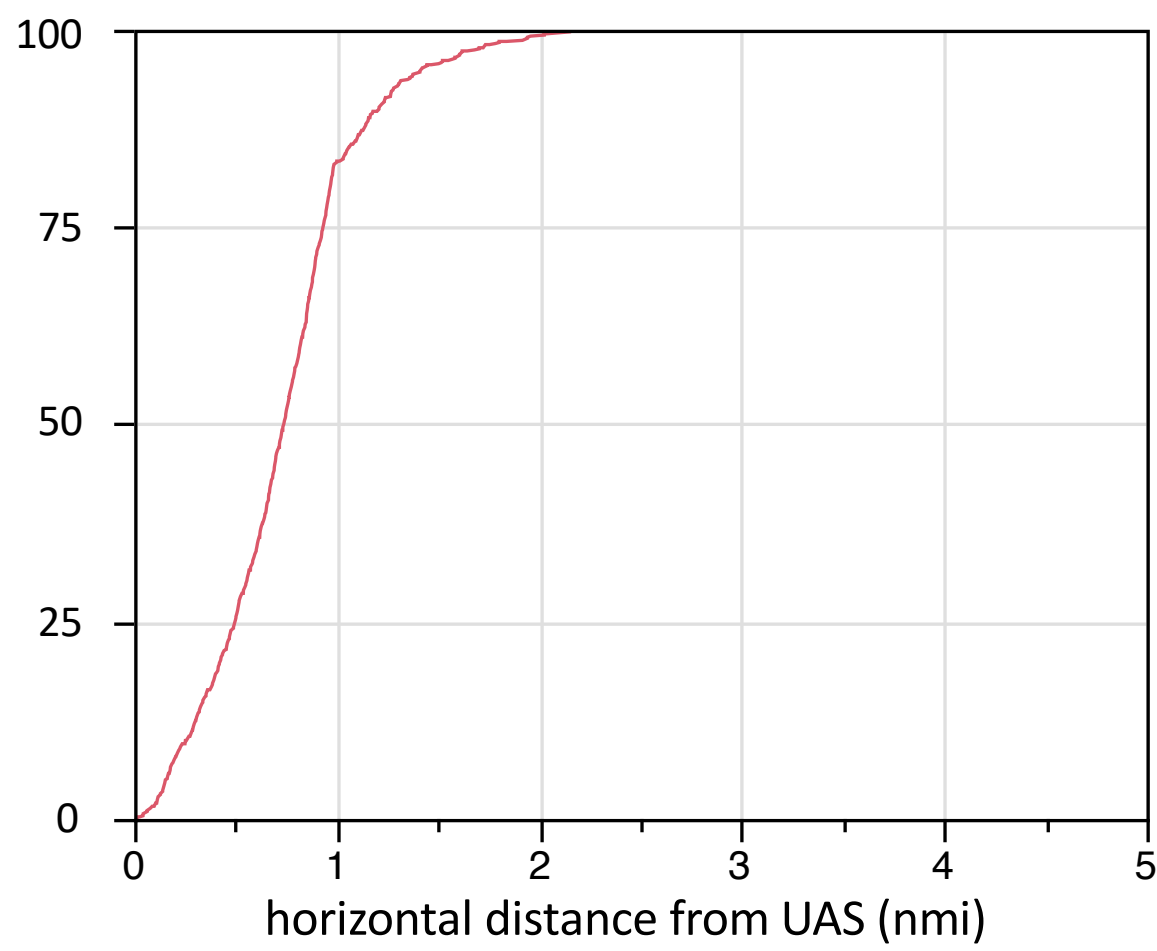

Cumulative distribution for vertical angle

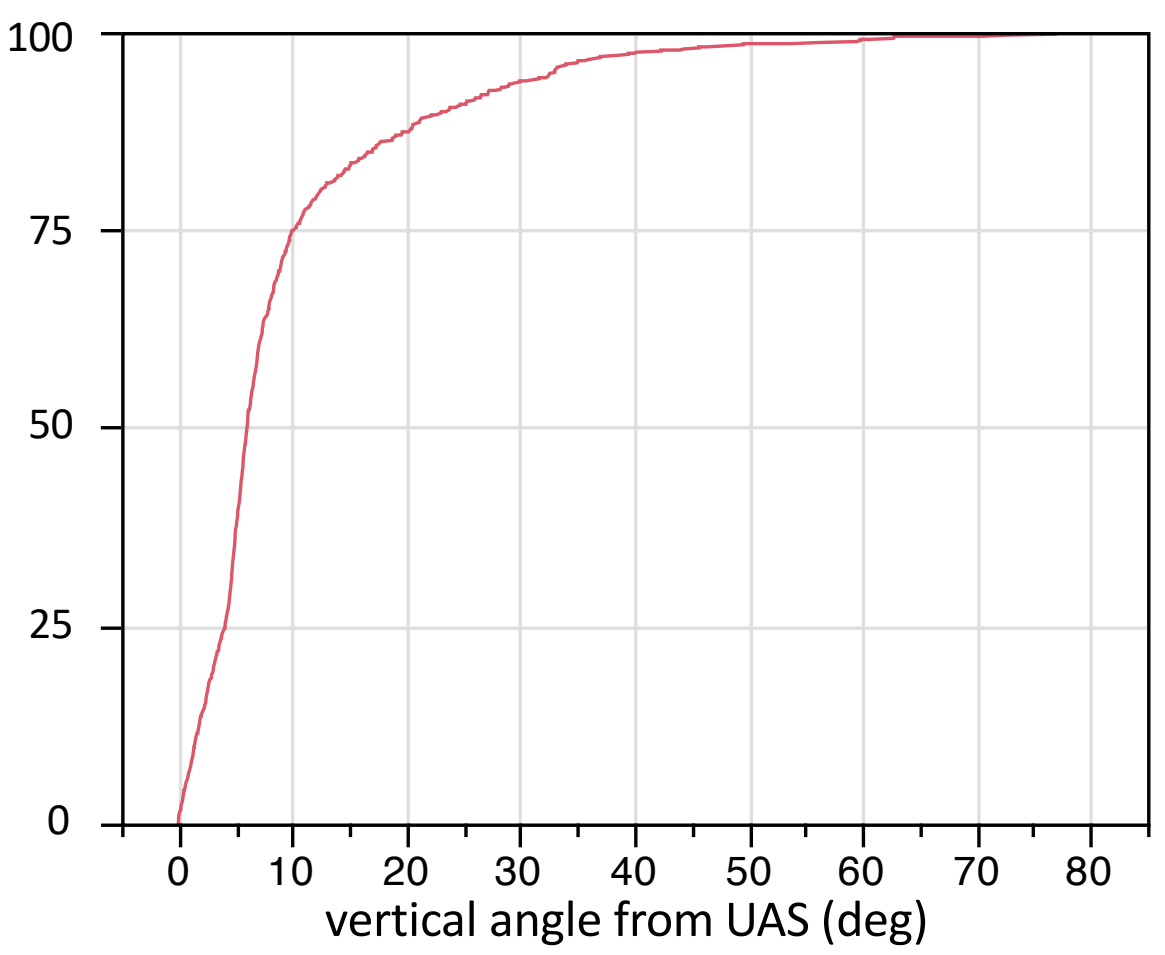

* The undetected WCVs might be detected if UAS is equipped with a secondary sensor having short detection range ( 2 nmi) but wide vFOR ( 60 deg) 


\section{Example: Undetected but Already Seen Before}

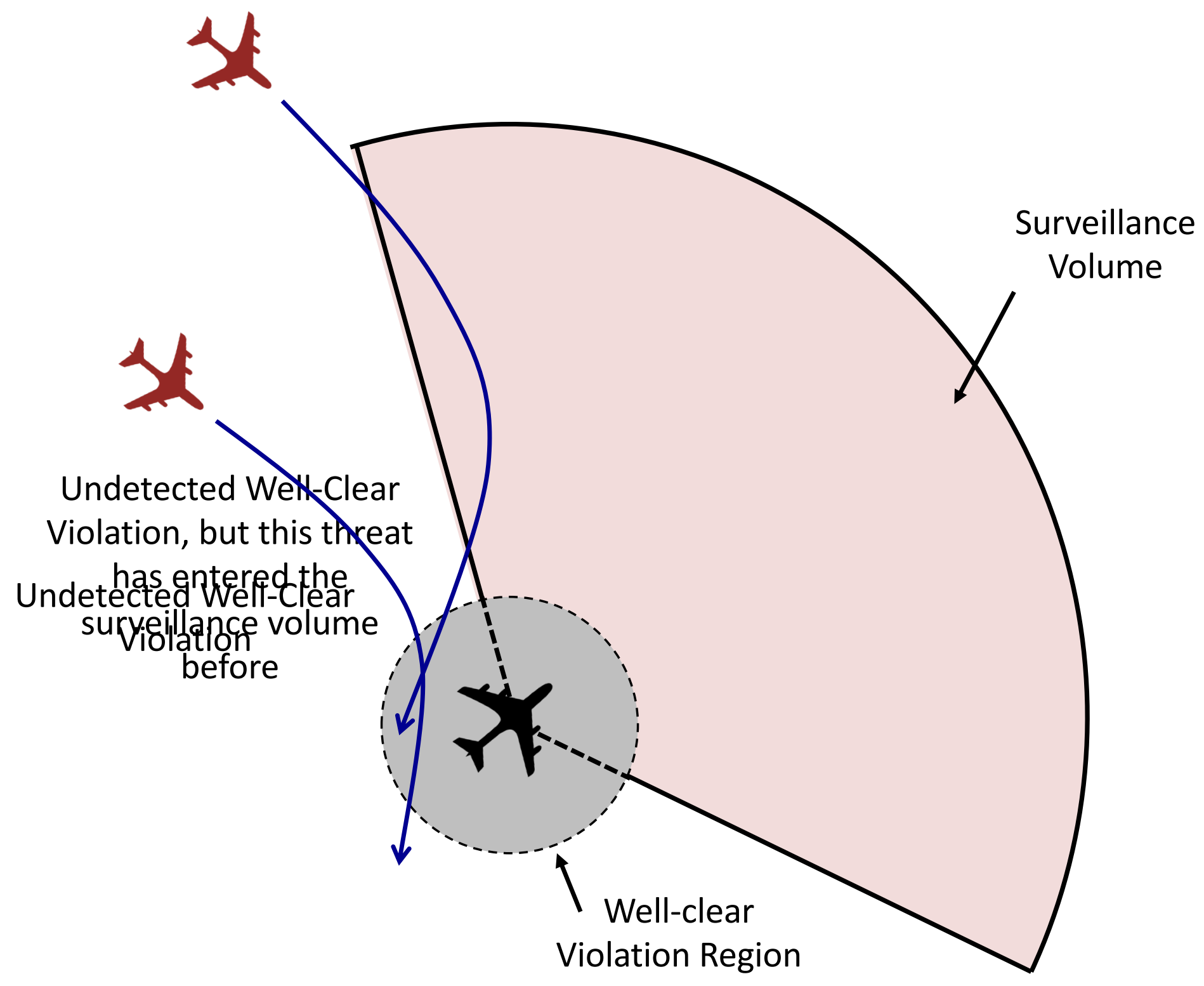




\section{Undetected Well-Clear Violation but the Threat Was Seen Before}

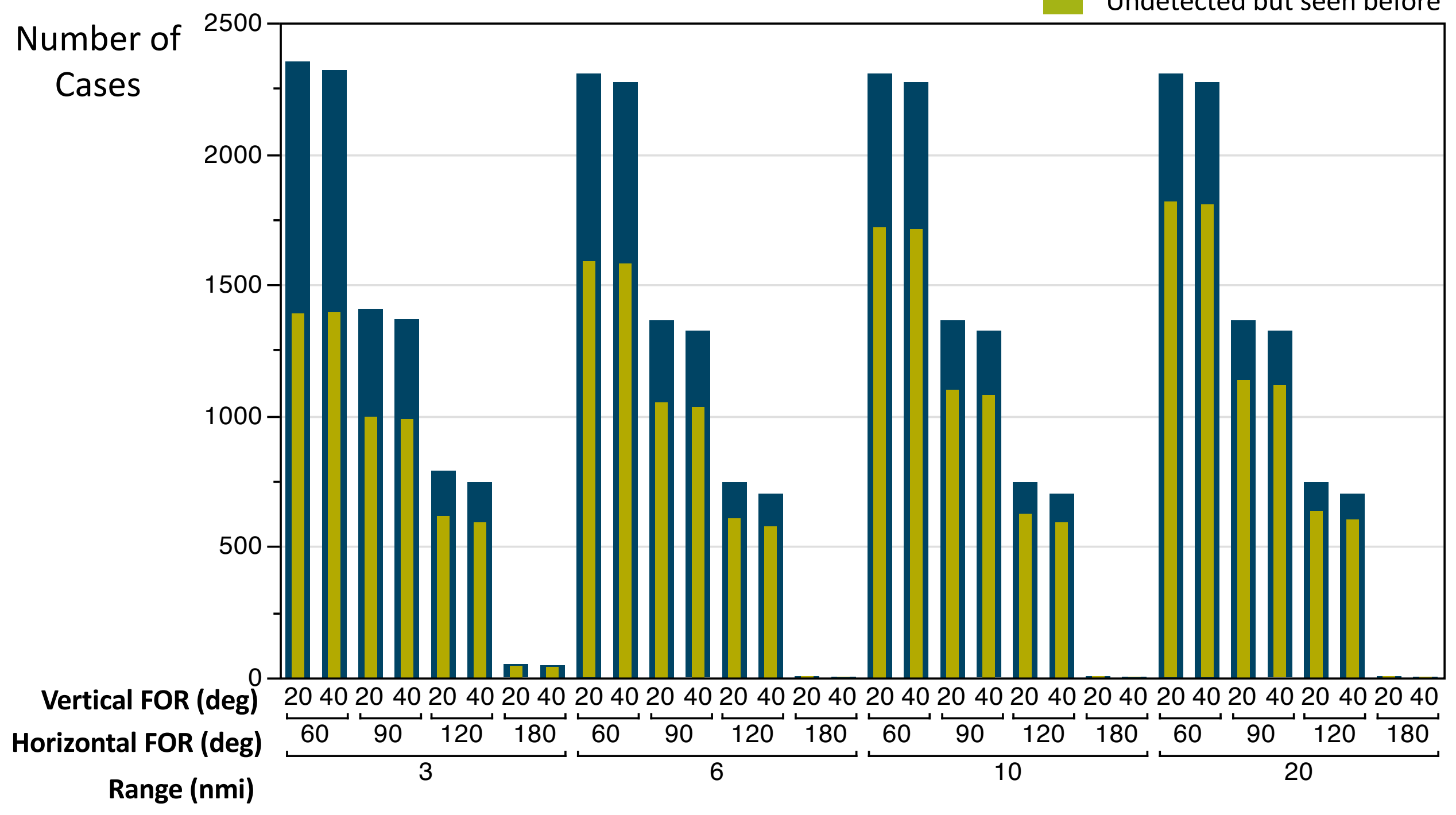

Undetected WCV

Undetected but seen before 


\section{Undetected Well-Clear Violation but the Threat Was Seen Before}

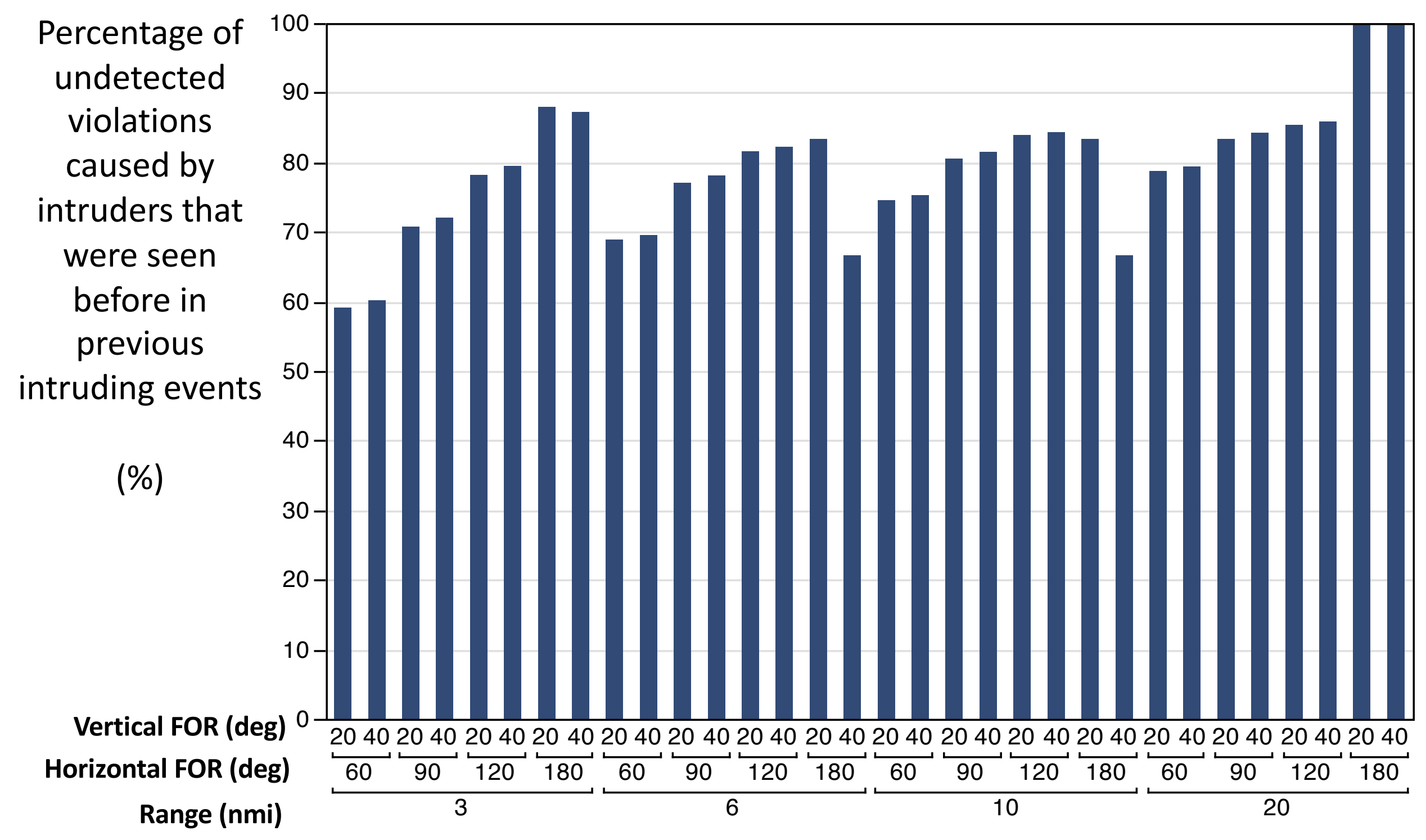




\section{Time until Well-clear Violation}

\section{at First Appearance in the Surveillance Volume}

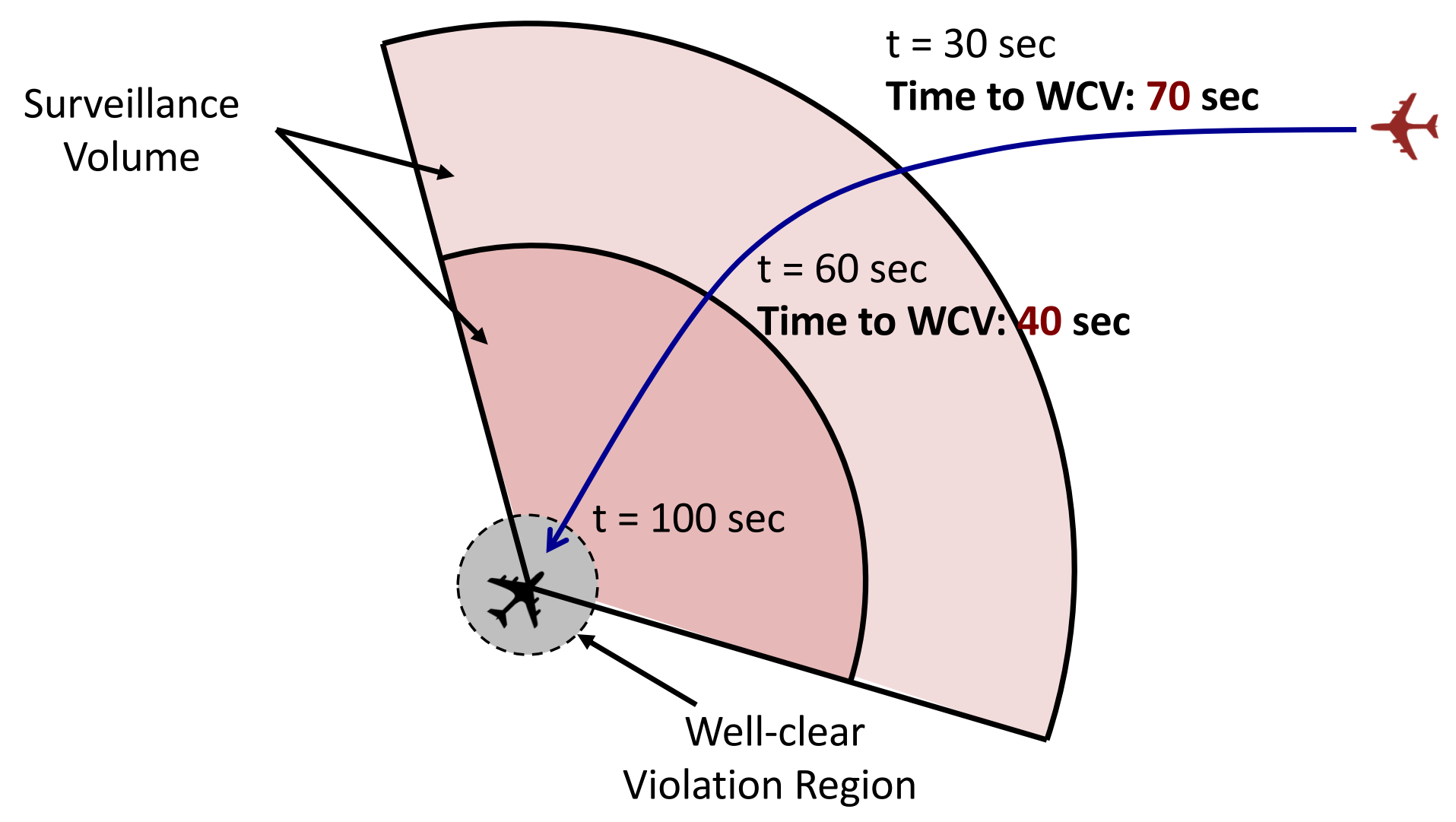

- Time until well-clear violation at the first appearance in the surveillance volume is important since it is time for preparing for avoiding the violation.

- For all threats, collect data at the time when they first appear in each surveillance volume. 


\section{Average Time until Well-Clear Violation at First Appearance in the Surveillance Volume}

Average time to well-clear violation when intruders first

appear in the surveillance volume

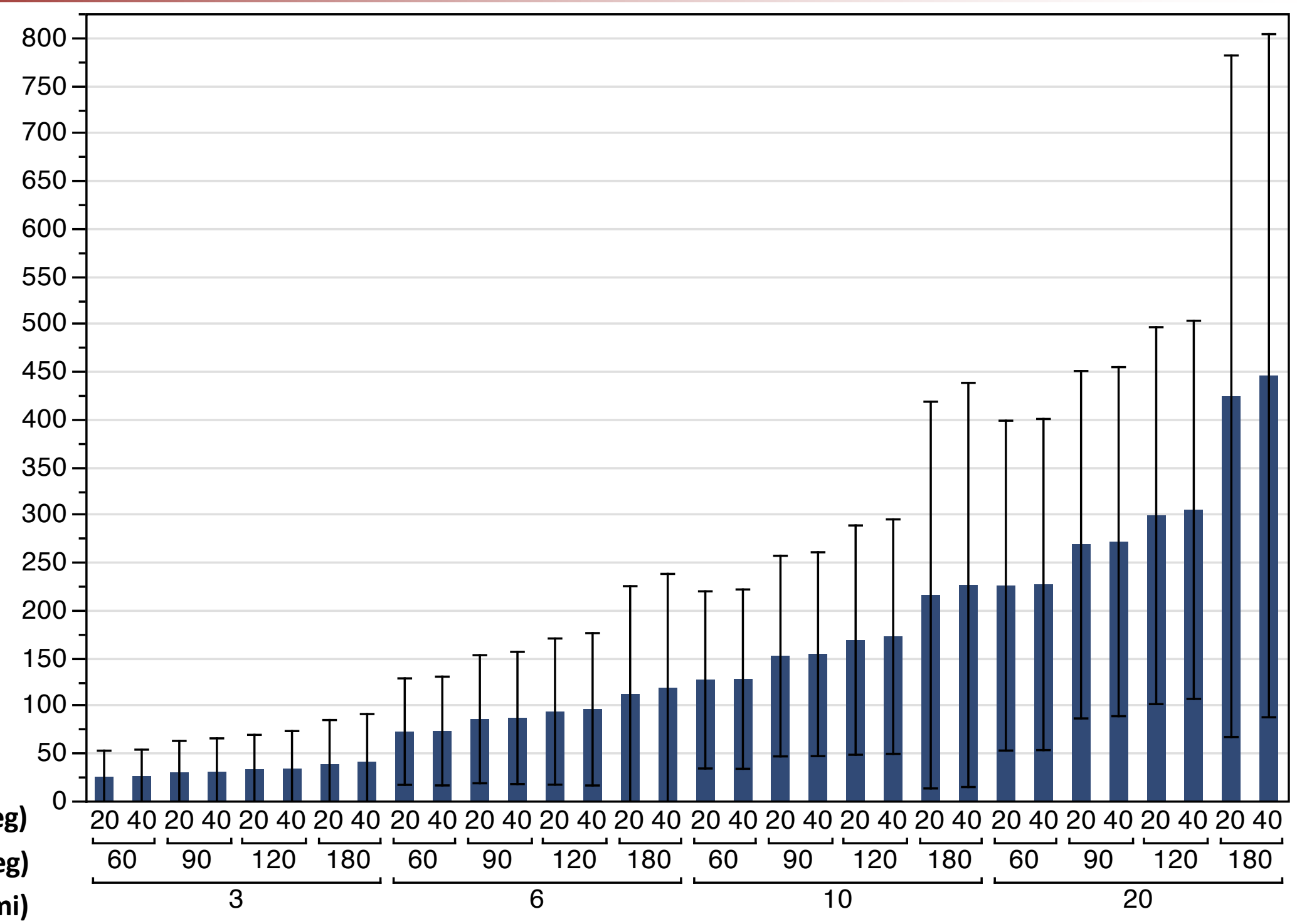

Range (nmi) 


\section{$40 \mathrm{sec}$ before Well-clear Violations}

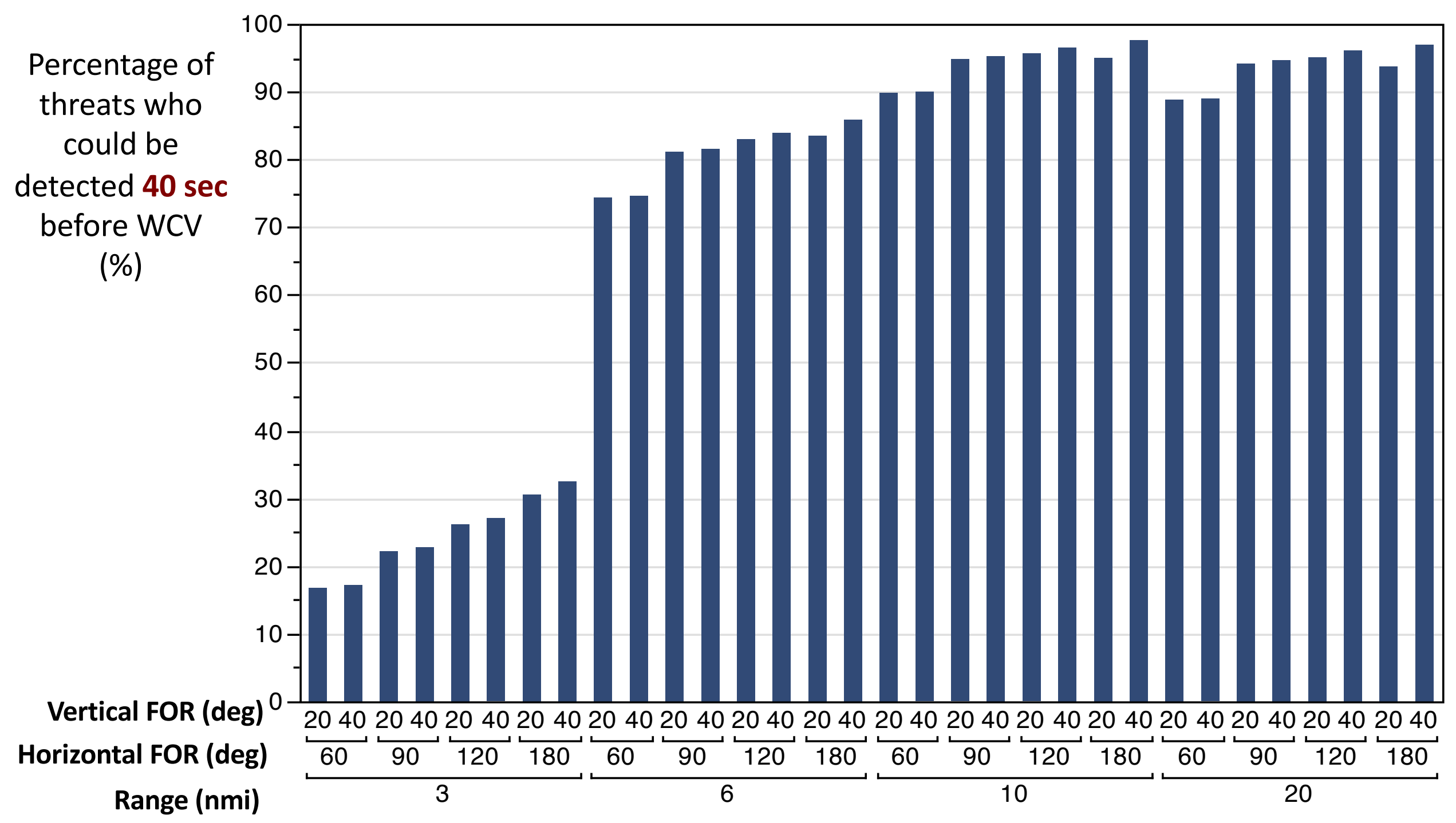




\section{0 sec before Well-clear Violations}

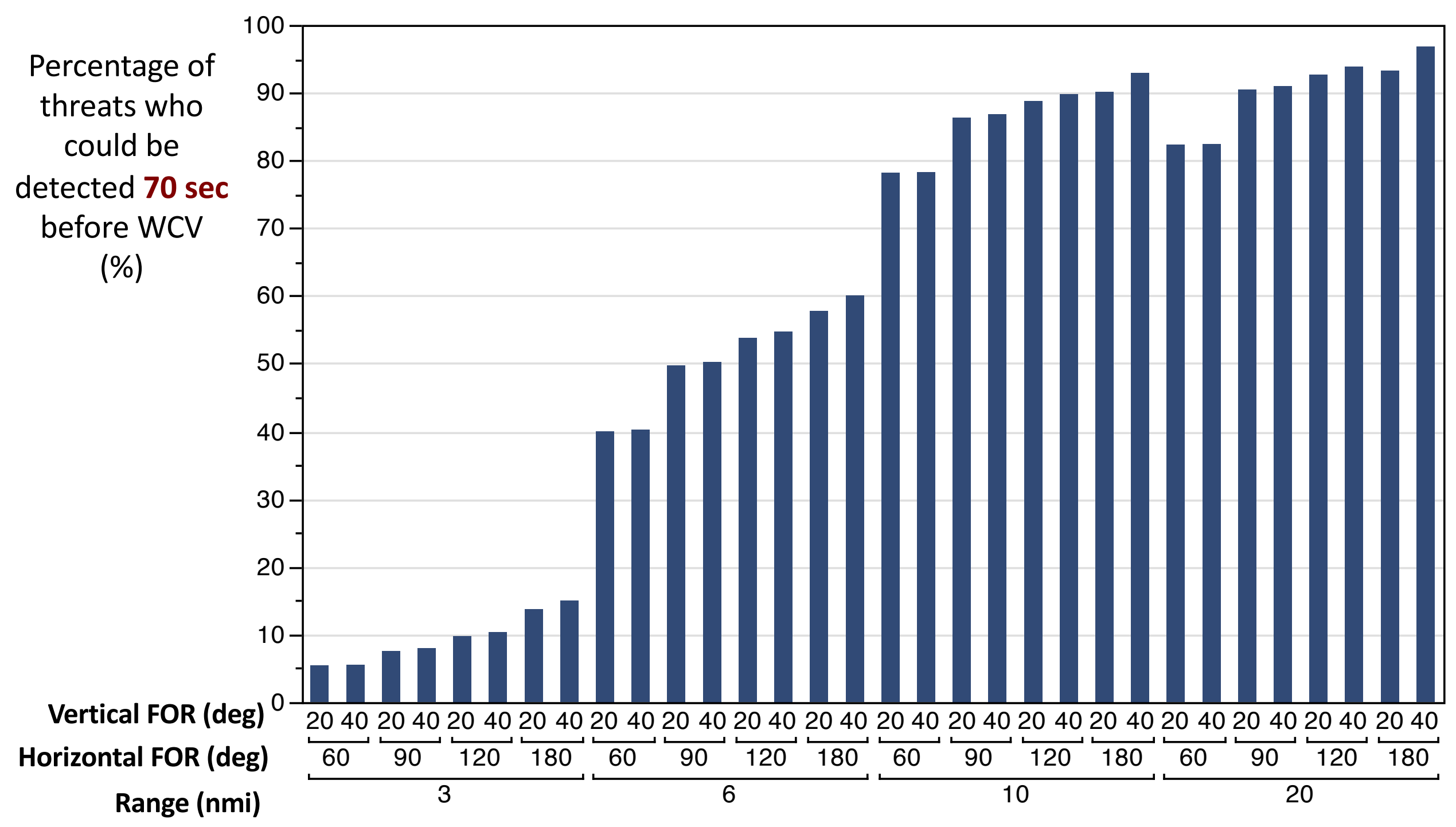




\section{Analysis of the Time to WCV}

Percentage of
threats who could be detected at a given time to WCV

(\%)

\begin{tabular}{|c|}
\hline $\begin{array}{l}\text { Horizontal field of } \\
\text { regard (deg) }\end{array}$ \\
\hline 60 \\
\hline 90 \\
\hline 12 \\
\hline 0 \\
\hline 18 \\
\hline $\begin{array}{l}\text { Vertical field of } \\
\text { regard (deg) }\end{array}$ \\
\hline-20 \\
\hline ...... 40 \\
\hline
\end{tabular}

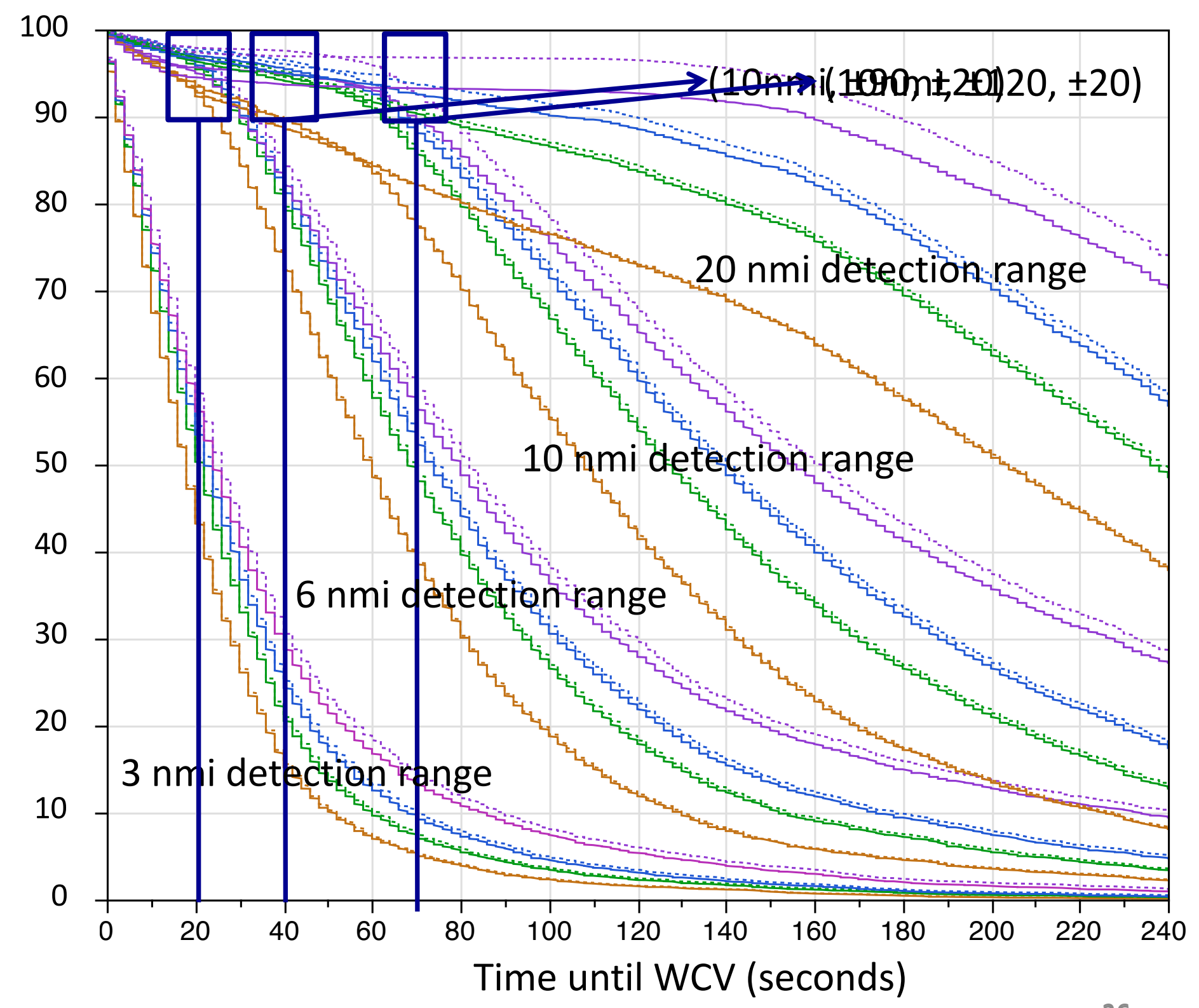




\section{Concluding Remarks}

- Analyzed and built a database for well-clear violations between UAS and VFR traffic

- Provide system designers a method to conduct trade space analysis among surveillance parameter values to meet overall system safety metrics

- Observed from a database of this study that

- The ratio of undetected Well-Clear Violations was substantially affected by horizontal field of regard

- More than $60 \%$ of undetected well-clear violations were incurred by the intruders that were seen in the surveillance volumes before

- The time to Well-Clear Violations was most sensitive to surveillance detection range 


\section{Future Research}

- Extend the current unmitigated surveillance study by

- Using high-fidelity sensor models

- Running ACES simulations with non-cooperative VFR flights and different UAS missions

- Investigating the effect of the SARP-recommended definition of well-clear separation standard

- Conduct mitigated surveillance study with a Detectand-Avoid system 


\title{
Questions?
}

- Chunki Park, Seung Man Lee, and Eric Mueller, "Investigating Detectand-Avoid Surveillance Performance for Unmanned Aircraft Systems", Proceedings of 14th AIAA Aviation Technology, Integration, and Operations (ATIO) Conference, Atlanta, GA, June 2014.

Contact Information

\author{
Chunki Park \\ chunki.park@nasa.gov
}

